\title{
DISCUSSION
}

\section{Soil-foundation modelling in laterally loaded historical towers}

\author{
F. PISANÒ* , C. G. DI PRISCO* , R. LANCELLOTTA* and G. MESRI†
}

\section{Contribution by G. Mesri}

Pisanò et al. (2014) correctly state that in the seismic stability analysis of historical towers the choice of an appropriate value of undrained shear strength deserves special attention. Therefore, the 700-year aging of Modena clay underlying the Ghirlandina bell tower should not be neglected. Mesri et al. (1997), using the preconsolidation pressure resulting from some 500 years of post-construction aging of Pancone clay underlying the Leaning Tower of Pisa, explained why the preservation lead ingots stacked at the north rim, producing effective vertical stresses in the recompression range, did not significantly correct the lean of the tower.

Before examining the post-construction aging effect on undrained shear strength of Modena clay underlying the Ghirlandina bell tower, for reference the discusser has computed the undrained shear strength of the clay in the free field using the laboratory $\sigma_{\mathrm{p}}^{\prime}$ and field $q_{\mathrm{c}}$ data in Fig. 5. The values of $\sigma_{\mathrm{p}}^{\prime}$ and $q_{\mathrm{c}}$ in Table 5 were read at 5, 10, 15 and $20 \mathrm{~m}$ depths using a linear variation of both $\sigma_{\mathrm{p}}^{\prime}$ and $q_{\mathrm{c}}$ with depth through the measurements. The mobilised undrained shear strength in the free field was computed using (Mesri, 1975, 1989; Terzaghi et al., 1996)

$$
s_{\text {uo }}(\mathrm{mob})=0 \cdot 22 \sigma_{\mathrm{p}}^{\prime}
$$

and using (Mesri, 2001)

$$
s_{\mathrm{uo}}(\mathrm{mob})=\frac{q_{\mathrm{c}}-\sigma_{\mathrm{vo}}}{16}
$$

The computed values of $s_{\mathrm{uo}}(\mathrm{mob})$ in Table 5, according to equations (14) and (15), are quite comparable.

Under the slowly growing tower load between 1009 and 1319, following each construction load increment, Modena clay completed primary consolidation and some secondary compression, and then the clay aged for some 700 years by secondary compression and thixotropic hardening. In order to evaluate aging of the Modena clay underlying the Ghirlandina bell tower, the discusser has read the values of final effective vertical stress, $\sigma_{\mathrm{vf}}^{\prime}$, at 5, 10, 15 and $20 \mathrm{~m}$ depths in Fig. 7, computed $\sigma_{\mathrm{vf}}^{\prime} / \sigma_{\mathrm{vo}}^{\prime}$, and compared this to preconstruction $\sigma_{\mathrm{p}}^{\prime} / \sigma_{\text {vo }}^{\prime}$ in Table 6 . In all depths at $x=0$ and $x= \pm 9.2 \mathrm{~m}$ (except at $z=5 \mathrm{~m}$ and $x= \pm 9.2 \mathrm{~m}$ ), $\sigma_{\mathrm{vf}}^{\prime} / \sigma_{\mathrm{vo}}^{\prime}$ exceeds the pre-tower construction $\sigma_{\mathrm{p}}^{\prime} / \sigma_{\mathrm{vo}}^{\prime}$, and therefore, these subsoil elements were loaded to the compression range. In all depths, at $x= \pm 27 \cdot 2 \mathrm{~m}$, the values of $\sigma_{\mathrm{vf}}^{\prime} / \sigma_{\mathrm{vo}}^{\prime}$ are less than $\sigma_{\mathrm{p}}^{\prime} / \sigma_{\mathrm{vo}}^{\prime}$; therefore, these elements of Modena clay were loaded to the recompression range. All elements have experienced some 700 years of aging by secondary compression and thixotropic hardening. For the elements in the compression range, a preconsolidation pressure by aging, $\sigma_{\mathrm{c}}^{\prime}$, has developed according to (Mesri, 1993)

* Politecnico di Milano, Milano, Italy.

$\dagger$ Ralph B. Peck Professor of Civil Engineering, University of Illinois at Urbana-Champaign, IL 61801, USA.

$$
\frac{\sigma_{\mathrm{vc}}^{\prime}}{\sigma_{\mathrm{vf}}^{\prime}}=\left(\frac{t}{t_{\mathrm{p}}}\right)^{\frac{C_{\alpha} / C_{\mathrm{c}}}{1-C_{\mathrm{r}} / C_{\mathrm{c}}}+\beta}
$$

where $t$ is the duration of consolidation (in this case about 700 years), and $t_{\mathrm{p}}$ is the duration of primary consolidation under the last construction load increment. (The value $t_{\mathrm{p}}$ is expected to be quite small because during the 310 -year slow construction period, secondary compression followed each construction load increment, and therefore, the last construction load increment was in the recompression range, and $t_{\mathrm{p}}$ was likely to have been less than 10 years and probably close to 1 year.) In the absence of data for Modena clay, the discusser has used $C_{\alpha} / C_{\mathrm{c}}=0.034$ of the Pancon clay (Mesri et al., 1997), $C_{\mathrm{r}} / C_{\mathrm{c}}=0.05$, and parameter of thixotropic hardening $\beta=0.02$. According to equation (D3), $\sigma_{\mathrm{vc}}^{\prime} / \sigma_{\mathrm{vf}}^{\prime}=1.44$ for $t_{\mathrm{p}}=1$ year, and $\sigma_{\mathrm{vc}}^{\prime} / \sigma_{\mathrm{vf}}^{\prime}=1.27$ for $t_{\mathrm{p}}=10$ years, leading to a representative value of the aging factor $\sigma_{\mathrm{vc}}^{\prime} / \sigma_{\mathrm{vf}}^{\prime}=1 \cdot 35$. Thus, for the values of $\sigma_{\mathrm{vf}}^{\prime} / \sigma_{\mathrm{vo}}^{\prime}$ equal or greater than pre-construction $\sigma_{\mathrm{p}}^{\prime} / \sigma_{\mathrm{vo}}^{\prime}$

$$
\begin{aligned}
& s_{\mathrm{u}}(\mathrm{mob})=(0 \cdot 22) \frac{\sigma_{\mathrm{vc}}^{\prime}}{\sigma_{\mathrm{vf}}^{\prime}} \sigma_{\mathrm{vf}}^{\prime} \\
& s_{\mathrm{u}}(\mathrm{mob})=(0 \cdot 22)(1 \cdot 35) \sigma_{\mathrm{vf}}^{\prime}
\end{aligned}
$$

As an example, at $x=0, z=5 \mathrm{~m}, \sigma_{\mathrm{vf}}^{\prime}=600 \mathrm{kPa}$, and according to equation $(17 \mathrm{a}), s_{\mathrm{u}}(\mathrm{mob})=132 \mathrm{kPa}$, whereas equation $(17 \mathrm{~b})$ predicts $s_{\mathrm{u}}(\mathrm{mob})=178 \mathrm{kPa}$.

For elements with $\sigma_{\mathrm{vf}}^{\prime} / \sigma_{\mathrm{vo}}^{\prime}=1, s_{\mathrm{u}}(\mathrm{mob})=s_{\mathrm{uo}}(\mathrm{mob})$ which is obtained commonly from equation (14) (Terzaghi et al., 1996). For the soil elements loaded to the recompression range, the aging effect on undrained shear strength depends on $\sigma_{\mathrm{vf}}^{\prime} / \sigma_{\mathrm{p}}^{\prime}$, and aging factor increases to 1.35 as $\sigma_{\mathrm{vf}}^{\prime} / \sigma_{\mathrm{p}}^{\prime}$ approaches one. For the data in Table 6 , at $x= \pm 27 \cdot 2 \mathrm{~m}$, the values of $\sigma_{\mathrm{vf}}^{\prime} / \sigma_{\mathrm{p}}^{\prime}$ are near 0.60 for the depth range of 5$20 \mathrm{~m}$, and the aging effect on undrained shear strength is negligible.

In summary, for the Modena clay elements underlying the Ghirandina bell tower that were loaded to the compression range beyond pre-construction $\sigma_{\mathrm{p}}^{\prime}$, an aging factor of 1.35 should be included in the mobilised undrained shear strength that is used in a seismic stability analysis.

\section{Authors' reply}

The interest of Professor Mesri in the authors' original paper is much appreciated, because it offers the opportunity to debate the relevant issue of time effects in geotechnical engineering.

The first aspect concerns the influence of aging on the preconsolidation stress (Mesri, 1993) and, as a consequence, on the evaluation of the mobilised, undrained, shear strength (Mesri, 1975; Jamiolkowski et al., 1985). In fact, when assessing the seismic vulnerability of historical buildings, such as the Ghirlandina tower, a sound estimation of the soil's undrained strength is of paramount importance, so that the conceptual path suggested by Professor Mesri should certainly be taken into proper account.

Further, creep phenomena affect not only the soil strength, 
Table 5. Mobilised undrained shear strength of Modena clay in the free field, $s_{\mathrm{uo}}(\mathrm{mob})$, computed using preconsolidation pressure or cone tip resistance

\begin{tabular}{l|c|c|c|c|c|c}
\hline Depth: $\mathrm{m}$ & $\sigma_{\text {vo }}^{\prime}: \mathrm{kPa}$ & $\sigma_{\mathrm{vo}}: \mathrm{kPa}$ & $\sigma_{\mathrm{p}}^{\prime}: \mathrm{kPa}$ & $q_{\mathrm{c}}: \mathrm{MPa}$ & $s_{\text {uo }}=0 \cdot 22 \sigma_{\mathrm{p}}^{\prime}: \mathrm{kPa}$ & $s_{\text {uo }}=\left(q_{\mathrm{c}}-\sigma_{\mathrm{v}}\right) / 16: \mathrm{kPa}$ \\
\hline 5 & 50 & 90 & 170 & $0 \cdot 7$ & 37 & 38 \\
10 & 100 & 190 & 240 & $1 \cdot 0$ & 53 & 51 \\
15 & 150 & 290 & 310 & $1 \cdot 3$ & 68 & 63 \\
20 & 200 & 390 & 400 & $1 \cdot 7$ & 88 & 82 \\
\hline
\end{tabular}

Table 6. Consolidation pressure on Modena clay underlying Ghirlandina bell tower

\begin{tabular}{|c|c|c|c|c|c|c|c|c|c|}
\hline \multicolumn{4}{|c|}{ Freefield } & \multicolumn{6}{|c|}{ Underlying Ghirlandina bell tower } \\
\hline \multirow[t]{2}{*}{ Depth: m } & \multirow[t]{2}{*}{$\sigma_{\mathrm{vo}}^{\prime}: \mathrm{kPa}$} & \multirow[t]{2}{*}{$\sigma_{\mathrm{p}}^{\prime}: \mathrm{kPa}$} & \multirow[t]{2}{*}{$\sigma_{\mathrm{p}}^{\prime} / \sigma_{\mathrm{vo}}^{\prime}$} & $\sigma_{\mathrm{vf}}^{\prime}: \mathrm{kPa}$ & $\sigma_{\mathrm{vf}}^{\prime} / \sigma_{\mathrm{vo}}^{\prime}$ & $\sigma_{\mathrm{vf}}^{\prime}: \mathrm{kPa}$ & $\sigma_{\mathrm{vf}}^{\prime} / \sigma_{\mathrm{vo}}^{\prime}$ & $\sigma_{\mathrm{vf}}^{\prime}: \mathrm{kPa}$ & $\sigma_{\mathrm{vf}}^{\prime} / \sigma_{\mathrm{vo}}^{\prime}$ \\
\hline & & & & \multicolumn{2}{|c|}{$x=0$} & \multicolumn{2}{|c|}{$x= \pm 9 \cdot 2 \mathrm{~m}$} & \multicolumn{2}{|c|}{$x= \pm 27 \cdot 2 \mathrm{~m}$} \\
\hline $\begin{array}{l}5 \\
10 \\
15 \\
20\end{array}$ & $\begin{array}{r}50 \\
100 \\
150 \\
200\end{array}$ & $\begin{array}{l}170 \\
240 \\
310 \\
400\end{array}$ & $\begin{array}{l}3 \cdot 40 \\
2 \cdot 40 \\
2 \cdot 07 \\
2 \cdot 00\end{array}$ & $\begin{array}{l}600 \\
610 \\
580 \\
510\end{array}$ & $\begin{array}{c}12 \cdot 0 \\
6 \cdot 10 \\
3 \cdot 87 \\
2 \cdot 55\end{array}$ & $\begin{array}{l}130 \\
260 \\
330 \\
375\end{array}$ & $\begin{array}{l}2 \cdot 60 \\
2 \cdot 60 \\
2 \cdot 20 \\
2 \cdot 55\end{array}$ & $\begin{array}{l}100 \\
145 \\
195 \\
250\end{array}$ & $\begin{array}{l}2 \cdot 00 \\
1 \cdot 45 \\
1 \cdot 30 \\
1 \cdot 25\end{array}$ \\
\hline
\end{tabular}

but also the pre-failure compliance of the material. As was discussed by Nova (1982), this aspect can be readily grasped and interpreted in the framework of work-hardening elastoplasticity. The occurrence of drained creep processes can in fact be associated with the expansion of the local elastic domain, whereas the stress state remains unaltered. When substantial creep has taken place, the current stress point lies within the (expanded) yield locus, and an elastic stiffness is exhibited by the soil upon loading (until the condition for further plastifications is newly fulfilled). The time-dependent soil behaviour at the constitutive level plays an apparent role in determining the mechanical response of geo-structural systems, as was recently shown by Marchi et al. (2011) in the context of macro-element modelling, and experimentally corroborated by Lancellotta \& Sabia (2014). In particular, the experience gained by Lancellotta \& Sabia (2014) on the basis of identification techniques, clearly demonstrates the importance of soil-structure interaction in the dynamic response of the Ghirlandina tower; it was proven that the soil stiffness mobilised by environmental vibrations is actually the elastic stiffness.

Following from the above premises, the authors would like to point out how the issue raised by Professor Mesri has even broader implications, deserving further research efforts to be undertaken by the whole geotechnical community. However, it also worth remarking on the genuinely methodological focus of the paper being discussed: how to exploit finite-element results to lump the effect of inhomogeneous, undrained strength distributions into a macro-element model, which is believed to be particularly suitable for soil-structure interaction analyses.

\section{REFERENCES}

Jamiolkowski, M., Ladd, C. C., Germaine, J. T. \& Lancellotta, R. (1985). New developments in field and laboratory testing of soils. Theme lecture. Proceedings of the 11th international conference on soil mechanics and foundation engineering, San Francisco, vol. 1, pp. 57-152. Rotterdam, the Netherlands: Balkema.

Lancellotta, R. \& Sabia, D. (2014). Identification technique for soil-structure analysis of the Ghirlandina tower. Int. J. Architectural Heritage (in press).

Marchi, M., Butterfield, R., Gottardi, G. \& Lancellotta, R. (2011), Stability and strength analysis of leaning towers. Géotechnique 61, No. 12, 1069-1079, http://dx.doi.org/10.1680/geot.9.P.054.

Mesri, G. (1975). New design procedure for stability of soft clays. Discussion. J. Geotech. Engng Div., ASCE 101, No. GT4, 409-412.

Mesri, G. (1989). A re-evaluation of $s_{\mathrm{u}}(\mathrm{mob})=0 \cdot 22 \sigma_{\mathrm{p}}^{\prime}$ using laboratory shear tests. Can. Geotech. J. 26, No. 1, 162-164.

Mesri, G. (1993). Aging of soils. Simposio internacional sobre envejecimiento de suelos, Ciudad de Mexico (eds. A. R. Ellstein and H. M. L. Valverde). Mexico City, Mexico: Mexican Society of Geotechnical Engineering.

Mesri, G. (2001). Undrained shear strength of soft clays from push cone penetration test. Géotechnique 51, No. 2, 167-168, http:// dx.doi.org/10.1680/geot.2001.51.2.167.

Mesri, G. \& Choi, Y. K. (1985). The uniqueness of the end of primary void ratio-effective stress relationships. Proceedings of the 11th international conference on soil mechanics and foundation engineering, San Francisco, vol. 2, pp. 587-590. Rotterdam, the Netherlands: Balkema.

Mesri, G., Hedien, J. E. \& Shahien, M. (1997). Geotechnical characteristics and compression of Pisa clay. Proceedings of the 14th international conference on soil mechanics and foundation engineering, Hamburg, Germany, pp. 373-376. Rotterdam, the Netherlands, Balkema.

Nova, R. (1982). A viscoplastic constitutive model for normally consolidated clay. In Proceedings of the IUTAM symposium on deformation and failure of granular materials, Delft (ed. P. A. Vermeer and H. J. Luger), pp. 287-295. Rotterdam, the Netherlands, Balkema.

Pisanò, F., di Prisco, C. G. \& Lancellatta, R. (2014). Soil-foundation modelling in laterally loaded historical towers. Géotechnique 64, No. 1, 1-15, http://dx.doi.org/10.1680/geot.12.P.141.

Terzaghi, K., Peck, R. B. \& Mesri, G. (1996). Soil mechanics in engineering practice, 3rd edn. New York, NY, USA: Wiley. 